\title{
Patógenos florestais quarentenários para o Brasil
}

\author{
Celso Garcia Auer \\ Alvaro Figueredo dos Santos \\ Albino Grigoletti JunioR
}

\section{RESUMO}

Este trabalho resume as informações sobre os patógenos florestais registrados na lista $\mathrm{A} 1$, de pragas quarentenárias para a região do Comitê de Sanidade Vegetal do ConeSul (COSAVE). São apresentados aspectos como hospedeiros, sintomatologia, importância econômica e potencial de introdução e controle dos patógenos Bursaphelenchus xylophilus, Cronartium spp., Drepanopeziza populorum, Endocronartium harknessii, Erwinia salicis, Gimnosporangium spp., Mycosphaerella dearnessii, M. gibsonii e Xanthomonas populi. As principais vias de introdução destes patógenos seria na forma de sementes contaminadas ou em material para propagação vegetativa que esteja infectado. A melhor medida de controle seria o tratamento de qualquer material vegetal importado, com os produtos recomendados para o patógeno quarentenário, o plantio e quarentena pós-ingresso em estufas sob inspeção contínua, até se garantir a sanidade das mudas, antes da liberação. Os plantios comerciais brasileiros de Pinus e Populus estão aparentemente resguardados, porém não foram listados patógenos quarentenários para $\mathrm{o}$ gênero Eucalyptus e para a acácia-negra. Um aspecto a ser ressaltado é a necessidade de um serviço de prospecção e vigilância para a detecção precoce destes patógenos, a fim de que sejam tomadas medidas para erradicação e controle.

PALAVRAS-CHAVE: bactéria, doença, espécies florestais, fitossanidade, fungo.

\section{ABSTRACT}

This article summarizes data about quarantine pathogens from A1 list, from quarantine pests for COSAVE region. Aspects as hosts, symptoms, economic importance, risks of introduction and control of Bursaphelenchus xylophilus, Cronartium spp., Drepanopeziza populorum, Endocronartium harknessii, Erwinia salicis, Gimnosporangium spp., Mycosphaerella dearnessii, M. gibsonii e Xanthomonas populi are presented. The ways of pathogen introductions are by contaminated seeds and infected material for vegetative propagation. The best control measure would be treating any imported vegetal material, with recommended products for quarantine pathogen 
before planting, further maintaining them in greenhouses with continuous inspection, in order to guarantee health conditions for seedlings before release. Brazilian commercial plantations of Pinus and Populus are covered, but quarantine pathogens for Eucalyptus and black wattle (Acacia mearnsii) were not listed. Aspects related to vigilance should be reinforced in order to prevent the entrance of these pathogens and establish adequate measures of control. Key words: bacteria, disease, forest trees, fungi, phytosanitary.

\section{INTRODUÇÃO}

Na região do Cone Sul da América do Sul, a ênfase dos programas de fomento florestal tem se concentrado na introdução de espécies exóticas, na maioria pertencentes aos gêneros Eucalyptus e Pinus e algumas salicáceas. Estas espécies constituem-se nas principais culturas de interesse para a região.

Considerando a importância econômica das espécies florestais exploradas na região, os possíveis danos e as possibilidades de ingresso através dos meios mais comuns derivados do intercâmbio comercial e científico de produtos florestais, criou-se o Grupo de Trabalho Permanente em Sanidade Silvi-Agrícola - GTPSSA, ligado ao Comitê de Sanidade Vegetal do Cone Sul COSAVE, em 1991. O GTPSSA definiu as pragas a serem incluídas na lista de pragas quarentenárias (lista A1), com base na discussão e análise das principais de pragas existentes fora da região do MERCOSUL. potencialmente perigosas para as espécies florestais plantadas comercialmente pelos países constituintes do COSAVE (Argentina, Brasil, Chile, Paraguai e Uruguai).

Neste trabalho procurou-se fornecer informações importantes, para os sistemas nacionais de vigilância sanitária, acerca destas pragas quarentenárias: nome científico (autor) - fase sexual; nomes de outros estádios (assexuais); Sinonímia; hospedeiros principais e alternativos; distribuição geográfica; Importância econômica; Potencial de introdução controle e referências bibliográficas. Seguem as descrições dos patógenos quarentenários registrados para as espécies florestais da região do COSAVE-MERCOSUL.

Bursaphelenchus xylophilus (Steinel \& Buhrer) Nickle

SINONIMIA: Bursaphelenchus lignicolus

HOSPEDEIROS: as espécies consideradas suscetíveis são $P$. densiflora, P. engelmanii, $P$. halepensis, $P$. koraiensis, $P$. leiophylla, $P$. luchensis, P. monticola, P. mugo, P. muricata, P. nigra, P. oocarpa, $P$. pentaphylla, $P$. pinaster, $P$. pinea, $P$. ponderosa, $P$. radiata, $P$. rudis, $P$. strobiformis, $P$. sylvestris e $P$. thunbergii. São relatados como resistentes $P$. banksiana, $P$. bungeana, $P$. caribaea, $P$. contorta, $P$. echinata, $P$. elliottii, $P$. excelsa, $P$. palustris, $P$. pungens, $P$. resinosa, $P$. rigida, $P$. strobus, $P$. tabuliformis, $P$. taeda, $P$. taiwanensis e o híbrido $P$. thunbergii $\mathrm{x}$ massoniana.

SINTOMATOLOGIA: o nematóide é disseminado (transmitido) por besouros do gênero Monochamus spp., invade os tecidos vasculares dos 
pinheiros de forma extremamente rápida, causando murcha vascular e a morte rápida da árvore. Postula-se a existência de uma toxina causadora da murcha como metabólito de uma bactéria associada com o nematóide. O principal sintoma é a murcha e morte rápida das árvores atacadas. Após a entrada do patógeno na árvore, a doença se desenvolve em etapas: (1) redução e cessamento do fluxo de oleoresina dentro da árvore, (2) redução da transpiração da planta, (3) murcha e amarelecimento da folhagem e (4) morte da árvore, aproximadamente entre 30 e 40 dias após o aparecimento dos primeiros sintomas. No último estágio da doença, em árvores mortas, os nematóides são encontrados em grandes populações através do tronco, ramos e raízes.

IMPORTÂNCIA ECONÔMICA: este nematóide é conhecido há muitos anos, na América do Norte, onde causa poucos danos. Atualmente, o nematóide acha-se distribuído na América do Norte (EUA e Canadá), Ásia (China, Japão, Coréia do Sul e Taiwan) e Europa (Portugal). No Japão, causou considerável mortalidade em talhões nativos de $P$. thunbergii e $P$. densiflora. Em Hong Kong e sul da China causou a "morte súbita" de $P$. massoniana, $P$. pinaster e $P$. thunbergii. Os principais danos econômicos conhecidos foram relatados no Japão, expressos pelo tamanho da área florestal infestada, pela quantidade de perdas em madeira e outras conseqüências indiretas. Em 1981, cerca de 650.000 ha de florestas estavam infestados, representando $25 \%$ do país. As perdas anuais de madeira, no início da década de 80 , causada por $B$. xylophilus, chegaram a 2,4 milhões de m3, e a um milhão de m3 em 1995. O agravamento das perdas econômicas vieram com a detecção do nematóide em remessas de cavacos de madeira originários do Canadá e EUA, pelo serviço sanitário alfandegário da Finlândia, em 1984. Este fato levou ao embargo comercial de madeira e de vários produtos florestais originários dos EUA, Canadá e Japão.

POTENCIAL DE INTRODUÇÃO E CONTROLE: para se evitar a entrada de madeira contaminada com o nematóide, devem ser exigidos diferentes tratamentos quarentenários. Exigências como partida livre, inspeção de ingresso, tratamento químico ou com calor e exames microscópicos devem ser feitos para que a importação de madeira de áreas onde a praga esteja presente seja feita com segurança.

\section{Cronartium spp. (não europeu)}

Cronartium coleosporioides Arthur outro estádio: Peridermium stalactiforme (Diet.) Arth. \& Kern.

Cronartium comandrae Peck outro estádio: Peridermium pyriforme Pk.

Cronartium comptoniae Arthur outro estádio: Peridermium comptoniae Orton \& Adams 
Cronartium fusiforme Hedgec. \& Hunt ex Cumm.

outro estádio: Peridermium fusiforme Arth. \& Kern.

Sinonímia: Cronartium quercuum $\mathrm{f}$. sp. fusiforme

Cronartium himalayense Bagchee

outro estádio: Peridermium stalactiforme Bagchee

Cronartium kamtschaticum Joostad

outro estádio: Peridermium kurilense Dietel

Cronartium quercuum (Berk.) Miyabe ex Shirai

outro estádio: Peridermium cerebrum Hedgec. \& Long.

HOSPEDEIROS:

Cronartium coleosporioides

AECIAIS: em espécies de Pinus com duas e três acículas, como $P$. banksiana, $P$. contorta, $P$. jeffreyi e $P$. ponderosa.

TELIAIS: em Castilleja spp., Cordylanthus, Lamourouxia, Melampyrum lineare, Orthocarpus luteus, Pedicularis bracteosa, Rhinanthus crista-galli.

Cronartium comandrae

AECIAIS: em espécies de Pinus com duas e três acículas, como $P$. banksiana, $P$. contorta, $P$. mugo, $P$. nigra, $P$. ponderosa, $P$. pungens, $P$. sylvestris, P. taeda, P. attenuatta, P. echinata, P. elliottii, P. glabra, P. jeffreyi, $P$. pinaster, $P$. resinosa, $P$. rigida.

TELIAIS: em Comandra umbellata var. pallida (em locais secos), $C$. livida (em locais úmidos), C. richardiana.

Cronartium comptoniae

AECIAIS: em $P$. banksiana, $P$. contorta, $P$. muricata, $P$. nigra, $P$. ponderosa, $P$. radiata, $P$. pungens, $P$. sylvestris, $P$. coulteri, $P$. densiflora, $P$. mugo, $P$. taeda, $P$. attenuatta, $P$. echinata, $P$. elliottii, $P$. glabra, $P$. jeffreyi, $P$. pinaster, $P$. resinosa, $P$. rigida, $P$. virginiana.

TELIAIS: em Comptonia peregrina, Myrica cerifera, M. gale.

Cronartium fusiforme

AECIAIS: em P. caribaea, P. elliottii, P. nigra, P. taeda, P. cooperi, $P$. echinata, $P$. palustris, $P$. pseudostrobus, $P$. rigida, $P$. serotina, $P$. torreyana.

TELIAIS: em Quercus nigra e Q. phellos, Carya, Castanea spp. (quatro espécies), Castanopsis diversifolia, Fagus, Lithocarpus densiflorus, Ostrya.

Cronartium himalayense

AECIAIS: em P. roxburghii.

TELIAIS: em Swertia angustifolia, S. cordata, S. elata.

Cronartium kamtschaticum

AECIAIS: em $P$. cembra var. sibirica, $P$. pumila e provavelmente $P$. strobus.

TELIAIS: em Castilleja, Pedicularis e provavelmente Ribes.

Cronartium quercuum 
AECIAIS: em espécies de Pinus com duas e três acículas, como $P$. nigra, $P$. sylvestris, $P$. banksiana ( o hospedeiro tipo para f. sp. banksianae), $P$. clausa, P. densiflora, P. echinata (o hospedeiro tipo para f. sp. echinatae), $P$. glabra, $P$. kesiya, $P$. luchensis, $P$. massoniana, $P$. ponderosa, $P$. pungens, $P$. resinosa, $P$. rigida, $P$. tabulaeformis, $P$. thunbergii, $P$. virginiana ( o hospedeiro tipo para f. sp. virginianae). Os registros em $P$. elliottii e $P$. taeda referem-se provavelmente a $C$. fusiforme.

TELIAIS: em Quercus, Castanea dentata, C. pumila, Castanopsis, Ciclobalanopsis.

SINTOMATOLOGIA: em geral, os espermogônios e aécios são produzidos sobre Pinus na primavera e início do verão, de um a vários anos após a infecção. Estes esporos podem ser transportados por longas distâncias, pelo vento e infectar o hospedeiro alternativo (no qual formam-se os teliosporos), porém não reinfectam o pinheiro. Cerca de duas semanas após a infecção, aparecem as urédias sobre o hospedeiro alternativo. A produção sucessiva de urédias e reinfecção durante o verão resultam em altos níveis de infecção no hospedeiro alternativo. Os teliosporos são produzidos no final do verão e os pinheiros são infectados pelos basidiosporos levados pelo vento. Os basidiosporos originam-se da germinação dos teliosporos. A infecção dos basidiosporos, que ocorre no verão e outono, é usualmente limitada a uma área dentro de 1,5 km do hospedeiro alternativo, devido aos esporos serem delicados e de vida curta. O hospedeiro alternativo não pode ser reinfectado pelos basidiosporos. A infecção dos pinheiros pelos basidiosporos completa o ciclo de vida.

A duração do ciclo completo varia entre as ferrugens. Para $C$. comptoniae e C. quercuum os espermogônios ocorrem na primavera em um ano e não são trocados pelos aécios até o ano seguinte. Urédios sobre hospedeiros alternativos, ao contrário, usualmente aparecem dentro de um a três semanas após a infecção dos aeciosporos, dependendo das condições ambientais. Os télios surgem cerca de 15 dias depois. C. fusiforme penetra diretamente nas células epidérmicas, ocorre rápida e profusa colonização do mesófilo e endoderme, resultando em parcial ou completa dissolução da célula do hospedeiro. $\mathrm{O}$ micélio destas ferrugens pode sobreviver na casca dos pinheiros e nas galhas. $\mathrm{O}$ ataque ocorre principalmente em indivíduos vigorosos, não se observando algum tipo de predisposição, quando os hospedeiros estão sob condições adversas.

Algumas formae speciales têm sido definidas dentro de C. quercuum como f. sp. banksianae, f. sp. echinatae, f. sp. virginianae e f. sp. fusiforme e outras diferenciações ainda podem existir, porém merecem estudo mais aprofundado.

C. coleosporioides - o fungo cresce além do ponto de infecção matando progressivamente os ramos, e posteriormente a árvore toda. Mudas 
podem ser mortas também. Necrose ou formação de cancros de ponteiros podem ocorrer em associação com Atropellis piniphila (Weir) Lohm. \& Cash. Causa também mancha foliar de coloração amarelo-pálida em Castilleja.

C. comandrae - forma intumescimentos fusiformes, suaves, seguidos pela quebra da casca infectada. a disseminação do fungo na casca provoca o rápido estrangulamento do tronco. A morte de ramos está associada com patógenos secundários. Ramos e troncos estrangulados podem viver ainda por vários anos. Grandes cancros com copiosa exsudação de resina, especialmente em $P$. contorta e $P$. ponderosa, são comuns em grandes ramos e troncos. Espermogônios grandes, de cor laranja avermelhada (4-8 mm de diâmetro) aparecem sobre a casca intumescida de dois a três anos após a infecção inicial. Manchas foliares de cor amarelo pálido desenvolvem-se sobre folhas e haste de Comandra.

C. comptoniae - encontrado principalmente em mudas e árvores jovens, pois a maioria das árvores com quatro a 10 anos de idade podem sobreviver à infecção, com somente redução no vigor. Mudas infectadas apresentam intumescimentos na haste, tornam-se anãs, deformadas e freqüentemente produzem superbrotamento. Cancros perenes, com comprimento cerca de quatro vezes maior que a largura, podem ser encontrados em hastes e ramos intumecidos, mas raramente a mais que $2 \mathrm{~m}$ acima do solo.

C. fusiforme - forma típicas galhas alongadas, fusiformes, em hastes e ramos. Infecções antigas transformam-se em cancros, enquanto que em mudas resultam em superbrotamento. Em carvalhos, ocorrem manchas foliares imperceptíveis, que sob condições severas causam abscisão foliar.

C. himalayense - a exsudação de resina, cancros e rachaduras de casca são sintomas característicos. Plantas ficam anãs, fracamente desenvolvidas, e acículas caem precocemente. Espermogônios atravessam a casca, exsudando um fluido amarelo-alaranjado, e posteriormente surgem os eciosporos de mesma coloração.

C. kamtschaticum - a infecção é caracterizada por intumescimentos fusiformes da casca, sobre os quais formam-se os écios. Estes intumescimentos podem transformar-se em cancros.

C. quercuum - a lesão surge inicialmente como um leve intumescimento em um dos lados da haste, enlarga-se, torna-se esférica e finalmente alongada. Estas galhas alongadas ocorrem normalmente em ramos de pinheiros velhos, mas causam poucos danos. Infecções em mudas resultam em severo nanismo ou morte rápida. Galhas no tronco de $P$. virginiana resultam em lesões que se assemelham às galhas produzidas por Endocronartium harknessii. Dentro da galha, as hifas ocorrem principalmente nos raios sendo abundantes na casca e esparsas na madeira. Na primavera, eciosporos surgem através das casca das galhas em um arranjamento quase cerebróide. 
IMPORTÂNCIA ECONÔMICA: as ferrugens causadas por Cronartium são doenças importantes através do mundo, provocando malformação, vigor reduzido e morte de mudas e árvores. $C$. quercuum e $C$. himalayense são particularmente danosas em viveiros e plantios jovens. $C$. fusiforme é a doença florestal mais séria no sul dos EUA, especialmente em $P$. elliottii e $P$. taeda, atacando pinheiros logo após a germinação. Galhas estrangulantes da haste são muito danosas. $C$. comandrae pode matar mudas de $P$. taeda, em poucos anos, após a infecção. Danos severos, na forma de lesões basais, em mudas de $P$. contorta têm causado considerável redução no crescimento e mortalidade, notadamente onde o hospedeiro alternativo Comandra livida é abundante. C. comptoniae não é sério patógeno, em condições naturais ou sobre árvores com mais de quatro anos de idade, porém em certas localidades do Canadá (Quebec e Vancouver) pode ser importante em $P$. banksiana, $P$. contorta, $P$. muricata e $P$. radiata. As espécies de Cronartium estão assim distribuídas:

Cronartium coleosporioides, Cronartium comandrae, Cronartium comptoniae - no Canadá e EUA.

Cronartium fusiforme - no sudoeste dos EUA, sendo comum nos estados costeiros da Carolina do Sul ao Texas.

Cronartium himalayense - no Japão, ex-União Soviética (Ilhas Kuril, Kamchatka, Sakhalin, Sibéria).

Cronartium quercuum - na China, Índia, Japão, Coréia do Norte e do Sul, Filipinas, Taiwan, por todo o continente da América do Norte, na maioria dos países da América Central, do Caribe e Cuba. Na Europa o registro depende da confirmação do estádio uredinal Uredo quercuus pertencer realmente a $C$. quercuum

POTENCIAL DE INTRODUÇÃO E CONTROLE: estas ferrugens pode ser dispersas por meio da movimentação de eciosporos e podem sobreviver por períodos consideráveis neste estádio. Material vegetal de Pinus spp. e do hospedeiro alternativo infectados, originários de regiões onde a ferrugem ocorre, é o meio de introdução da doença. Como não existe risco de transmissão em sementes e pólen, estes devem ser empregados em trabalhos de introdução e melhoramento genético. No caso de introdução de material vegetativo, devem ser usadas medidas quarentenárias criteriosas. A única garantia é a proibição da entrada de plantas hospedeiras (especialmente Pinus e Quercus spp.) de países onde os patógenos ocorram, uma vez que os sintomas podem não estar aparentes. Caso haja importação de toras de Pinus, deve-se solicitar que venham sem casca e devem ser apropriadamente tratadas com secagem forçada, feita a fermentação, passar por aquecimento ou serem aplicados produtos químicos fungicidas, para a desinfestação. 


\section{SINONIMIA: Marssonina populi (Lib.) Magnus (fase assexual)}

HOSPEDEIROS: Segundo a literatura, são hospedeiros os choupos das seções Leuce, Aigeiros e Tacamahaca, notadamente Populus nigra, P. $x$ euroamericana e menos frequentemente em $P$. deltoides. É encontrado, também, sobre $P$. tacamahaca. As espécies $P$. berolinensis, $P$. adenopoda, $P$. tomentosa, $P$. tremuloides e $P$. nigra var. italica foram apresentadas como suscetíveis. Como híbridos suscetíveis existem $P$. "Blome de Garonne", $P$. "I214", P. "15A", P. x berolinensis, $P . x$ canadensis, $P . x$ robusta, $P . x$ canadensis cultivares Marilandica, Regenerata e Heidemij, $P$. deltoides x $P$. "Volga", P. nigra var. betulifolia x P. "Volga" e P. charkowiensis x P. robusta. Não existem relatos sobre a ocorrência de hospedeiros alternativos, como as espécies do gênero Salix. Com relação a possibilidade de outras Salicáceas serem hospedeiras de M. populi, a exemplo de Salix spp., não existem maiores informações. O único registro de Marssonina, no Brasil, envolve uma outra espécie, Marssonina salicicola (Bres.) Magn., causando antracnose em $S$. babylonica.

SINTOMATOLOGIA: $M$. populi causa lesões foliares, na forma de manchas irregulares pardas. Pode causar queima de ponteiros, particularmente em $P$. tremuloides. Nesta espécie, foi registrada uma epidemia em 1981, nos EUA, quando detectou-se que cerca de $50 \%$ das árvores atacadas apresentaram infecção variando a severidade de moderada a pesada, em uma área de 450 ha. No caso de intensa infecção, as manchas foliares induzem a desfolha prematura da copa. No leste da China, causa alta mortalidade de mudas e prematura queda de folhas de plantios comerciais e em exemplares ornamentais.

IMPORTÂNCIA ECONÔMICA: Os registros da ocorrência revelam como área de distribuição de M. populi: a América do Norte (Canadá e EUA), a Ásia (China e Japão), a Oceania (Nova Zelândia) e a maior parte da Europa (Bélgica, Russia, França, Irlanda, ex-Checoslovaquia).

O principal dano é a perda na produção de madeira, devido à intensa desfolha que ocorre em condições ambientais extremamente favoráveis à disseminação e colonização do patógeno.

POTENCIAL DE INTRODUÇÃO E CONTROLE: devido a mecanismos de competição entre as empresas que atualmente estão plantando choupo no Brasil, a tendência atual é que não haja intercâmbio de material genético. Assim, as empresas necessitam importar mais material genético, à medida que a populicultura for sendo desenvolvida, aumentando o risco de introdução de patógenos exóticos na região de cultivo.

De acordo com a literatura, a principal via de introdução de $M$. populi é por meio de estacas ou infectadas ou contaminadas, para propagação vegetativa. Não se encontrou maiores informações acerca da possibilidade de transmissão da doença, através do trânsito de material micropropagado, porém acredita-se que os tratamentos para desinfecção e contaminação de explantes devem eliminar qualquer tipo de inóculo de M. populi. 


\section{Erwinia salicis (Day) Chester}

SINONIMIA: Erwinia amylovora var. salicis

HOSPEDEIROS: as espécies mais suscetíveis são Salix alba, S. alba var. caerula e $S$. fragilis; as menos suscetíveis são $S$. amygdalina, $S$. caprea, $S$. cinerea, $S$. purpurea, S. russelliana, $S$. triandra, $S$. viminalis, $S$. viridis e $S$. vitelliana.

SINTOMATOLOGIA: a bactéria invade somente o tecido lenhoso (xilema) e provoca a podridão e a posterior morte da área afetada. As folhas murcham e ficam avermelhadas (red leaf) ao final da primavera e no verão os ramos afetados perdem as folhas e morrem. O tecido lenhoso das árvores doentes aparece manchado pela progressão da doença, que se estende no indivíduo através do xilema. Além da murcha e avermelhamento da folha, ocorre morte de ramos jovens e de brotações e queda de folhas. Nos pontos do tronco com xilema exposto, pode-se observar a exsudação de pús bacteriano incolor, que posteriormente torna-se acinzentado. Eventualmente, podem ocorrer morte de árvores.

A bactéria invade a madeira, persistindo de um ano para outro. Os novos anéis de crescimento anuais são invadidos, a partir dos anteriores, por meio de perfurações feitas por larvas de insetos. Outras bactérias secundárias foram encontradas, seguindo a infecção por E. salicis e que são responsáveis por outras modificações nos tecidos do hospedeiro.

Supostamente, ocorre dispersão natural por chuva e vento, que transportariam os exsudatos bacterianos de planta a planta. A entrada da bactéria nas árvores sadias seria por ferimentos existentes nos troncos, produzidos por diversos agentes. Existe suspeita de transmissão em lotes de madeira e embalagens de madeira infestados com a bactéria.

IMPORTÂNCIA ECONÔMICA: o patógeno encontra-se amplamente distribuído na Holanda e Japão e com distribuição restrita na Inglaterra. Na Austria foram encontradas árvores com manchas características na madeira, mas o patógeno não foi isolado e a enfermidade não foi confirmada ainda. Para o Brasil, o impacto está relacionado com a entrada de um patógeno exótico, o qual poderia atacar as populações nativas de Salix. Com relação ao setor produtivo, não existe a noção exata do impacto sobre os plantios com salicáceas, cujo uso varia de ornamental a plantios experimentais, em pequena escala. A doença pode, também, impedir o uso de Salix na recuperação de matas ciliares e áreas degradadas.

POTENCIAL DE INTRODUÇÃO E CONTROLE: a doença é transmitida, principalmente, por estacas infectadas. Existem evidências de transmissão por insetos vetores. $\mathrm{Na}$ Holanda, indicou-se o inseto Cryptorrhynchus lapathi como vetor, porém sem confirmação. O único controle efetivo recomendado é a constante inspeção para detectar o sintoma de 
"folha vermelha" e o corte imediato de todas árvores infectadas. Na Inglaterra, existem leis que obrigam os produtores a remover as árvores atacadas; este tratamento parece ter êxito, já que a enfermidade está cada vez menos comum.

\section{Gimnosporangium spp.}

HOSPEDEIROS: este fungo é importante para culturas de espécies frutíferas e ornamentais, as quais são os hospedeiros aeciais. A única espécie florestal atacada é Juniperus spp., que para alguns locais da região do COSAVE é plantada como ornamental.

G. asiaticum

AECIAIS: em Pyrus, Chaenomeles, Cydonia, Photinia.

TELIAIS: em Juniperus sect. Sabina (J. chinensis)

G. clavipes

AECIAIS: em Crataegus, Cydonia, Malus.

TELIAIS: em Juniperus sect. Oxycedrus (J. communis, J. sibirica) e $J$. sect. Sabina (J. virginianae)

G. globosum

AECIAIS: em Crataegus, Malus, Pyrus, Sorbus.

TELIAIS: em Juniperus sect. Sabina (J. virginianae)

G. juniperi-virginianae

AECIAIS: em Malus.

TELIAIS: em Juniperus sect. Sabina (J. virginianae e afins)

G. shiraianum

AECIAIS: em Pyrus.

TELIAIS: em Juniperus sect. Oxycedrus (J. conferta).

G. yamadae

AECIAIS: em Malus.

TELIAIS: em Juniperus sect. Sabina

SINTOMATOLOGIA: as espécies de Gymnosporangium causam galhas sobre ramos, galhos e folhas ou intumescimentos fusiformes sobre hastes e troncos (G. yamadae), o qual pode produzir massas teliais em ambiente úmido. Sobre os hospedeiros aeciais, os sintomas correspondem à observação de aécios e pícnios sobre as folhas. Sobre cultivares suscetiveis, G. juniperivirginianae e G. yamadae podem causar severa desfolha. infecções sobre frutos são raramente causados por G. globosum e G. yamadae. Ocasionalmente, G. junieri-virginianae causa lesões escuras necróticas sobre frutos de maçã. $G$. clavipes é mais perigosa sobre frutos e maçãs e pode causar lesões cinzaesverdeadas no fim do cálice floral, que se estende ao coração do fruto e distorções nos mesmos.

Todas as espécies de Gymnosporangium são ferrugens heteroécias, que necessitam de Juniperus e de rosáceas, para completar o seu ciclo de vida. Os teliosporos são produzidos sobre hastes, brotos verdes e folhas de Juniperus, 
na primavera. Em condições úmidas do ambiente, os teliosporos germinam e produzem basidiosporos, que dispersos, são capazes de infectar rosáceas próximas.

IMPORTÂNCIA ECONÔMICA: as espécies $G$. asiaticum e $G$. yamadae são conhecidas pelas doenças que causam, mas existe incerteza quanto a G. shiraianum. G. juniperi-virginianae é a espécie mais patogênica dentre as outras, nos EUA. G. clavipes pode atacar severamente frutos de maçã, enquanto que G. globosum ataca folhas de macieira (os frutos raramente são atacados) e Juniperus. A severidade da infecção de rosáceas (as mais importantes) é determinada pela proximidade de hospedeiros alternativos infectados. As espécies de Gymnosporangium estão assim distribuídas:

G. asiaticum: EUA (nos estados da California, Connecticut, Oregon e Washington), China, Hong Kong, Japão e Coréia.

G. clavipes: no Canadá, EUA, México.

G. globosum: na região leste do Canadá, México, EUA (nos estados do leste e Alaska).

G. juniperi-virginianae: no Canadá (Ontário, Quebec), EUA, (ao leste das Montanhas Rochosas e California).

G. shiraianum: Japão.

G. yamadae: China, Japão e Coréia.

POTENCIAL DE INTRODUÇÃO E CONTROLE: a inspeção de material de Juniperus importado com infecções latentes é importante. Um procedimento seguro de quarentena envolve a retenção de material suspeito em local protegido, por dois anos, e inspeções durante o período de primavera/verão. Todo material vegetativo de Juniperus proveniente da Ásia e América do Norte pode estar infectado. As ferrugens podem estar latentes durante o inverno e não ser detectado durante a certificação fitossanitária préexportação. A infecção também pode ter permanecido latente na estação de crescimento anterior. a introdução da doença em rosáceas não é viável, pois a infecção não é persistente no estágio dormente das plantas. O perigo é a introdução de hospedeiros no período de verão, quando as lesões estão ativas.

Como a infecção de Juniperus é sistêmica sobre hastes e copa, nenhum tratamento é totalmente eficiente. Se plantas ou estacas de Juniperus forem importadas da Ásia ou América do Norte, estas deverão ser mantidas em quarentena, por toda a estação de crescimento, até que se garanta a ausência do patógeno. As plantas ou partes de Juniperus devem ser procedentes de campos com um mínimo de dois anos de ausência de registo da doença. Plantas ou partes de Crataegus, Cydonia, Malus, Photinia e Pyrus procedentes da Ásia e América do Norte devem estar dormentes e livres de folhas.

Endocronartium harknessii (Moore) Hirat. outro estádio: Peridermium harknessii Moore 


\section{Sinonímia: Cronartium harknessii Meine} HOSPEDEIROS:

AECIAIS: em espécies de Pinus com duas e três acículas, como $P$. attenuatta, $P$. banksiana, $P$. contorta, $P$. halepensis, $P$. mugo, $P$. muricata, $P$. nigra, $P$. radiata, $P$. sylvestris e $P$. ponderosa.

TELIAIS: nenhum (ferrugem autoécia, com ciclo curto).

SINTOMATOLOGIA: na primavera, gotas de um líquido claro e viscoso são produzidas. Estas são seguidas por aécios de cor amarelo-pálido, com 1 a 8 mm de diâmetro, contendo esporos de cor amarelo-alaranjado em massa pulverulenta. Cada nova infecção é seguida pela formação de galha oblonga a esférica, bem delimitada, de até $8 \mathrm{~cm}$, algumas vezes acompanhada por uma pequena vassoura de bruxa. Pequenas galhas sobre brotações com um a dois anos de idade são freqüentemente piriformes. A casca solta-se em grandes escamas, expondo finalmente a madeira, com um colar de casca velha ao redor dos limites da galha. Galhas formam-se sobre ramos e pequenos troncos de Pinus de todas as idades.

O ciclo de vida é simples começando com teliosporos aecióides (esporos com características morfológicas de aeciosporos mas germinando e funcionando como teliosporos), que desenvolvem-se na primavera sobre galhas em ramos (raramente sobre cancros no tronco) de Pinus, cerca de dois a quatro anos após a infecção. Estes esporos são levados em correntes aéreas e reinfectam o Pinus, diretamente. Uma vez estabelecida, a galha continua a produzir esporos a cada primavera e a invasão por patógenos secundários, normalmente, resulta na morte do ramo. A ferrugem pode continuar a sobreviver em cancros por até 200 anos, mas produz poucos ou nenhum esporo.

IMPORTÂNCIA ECONÔMICA: o patógeno encontra-se distribuído por toda a América do Norte, prevalente na costa do Pacífico do Alaska, através do Canadá e EUA até o México e no leste da Nova Escócia (Canadá) ao estado de New York. Não existem registros confirmados na América Central e Caribe e América do Sul. A ferrugem causada por Endocronartium harknessii apresenta efeitos na forma, conteúdo de madeira e taxa de crescimento de Pinus e mata árvores isoladas. Galhas no tronco principal de árvores jovens pode levar à morte da árvore, mas galhas sobre ramos de árvores mais velhas causam poucas perdas. Vários surtos em mudas de $P$. ponderosa e $P$. contorta têm sido registrados no noroeste do Canadá, bem como sérios danos sobre formações florestais naturais de $P$. banksiana e $P$. sylvestris no Canadá. Danos em talhões comerciais ocorrem em $P$. contorta, na região das Montanhas Rochosas (EUA). Existem relatos de $P$. sylvestris ser menos suscetível que $P$. contorta.

POTENCIAL DE INTRODUÇÃO E CONTROLE: são válidas as informações em relação a Cronartium.

Mycosphaerella dearnessii Barr

SINONIMIA: Scirrihia acicola (Dearn.) Siggers 
HOSPEDEIROS: todo o gênero Pinus é potencialmente hospedeiro. Os hospedeiros altamente suscetíveis são Pinus elliottii, $P$. palustris, $P$. radiata, $P$. taeda, e $P$. thunbergii. As espécies moderadamente resistentes são $P$. attenuata, $P$. caribaea, $P$. kesiya, $P$. maximinoi, $P$. oocarpa, $P$. patula e $P$. tecunumanii. As espécies pouco suscetíveis são $P$. fenzeliana, $P$. massoniana $e$ $P$. taiwanensis. Pinus contorta, $P$. halepensis, $P$. muricata, $P$. pinaster, $P$. pinea, e $P$. sylvestris, porém. $P$. banksiana é considerado resistente.

SINTOMATOLOGIA: causa uma necrose marrom das acículas e subsequentemente, queima da mesma, sobre mudas com mais de quatro anos de idade em viveiros e sobre árvores jovens em plantios. Ocasionalmente algumas árvores adultas podem ser severamente atacadas. Plantas tornam-se tipicamente infectadas no centro da parte baixa da copa e a doença dissemina-se gradualmente para cima e para fora para as pontas dos ramos. Em muitas espécies, a copa das árvores é suscetível, incluindo acículas jovens primárias.

As lesões aparecem, primeiramente, como salpiques de coloração cinza, que posteriormente desenvolvem para pintas e faixas com centro necrótico escuro com margem amarelada. Um pigmento laranja ou avermelhado pode ser formado em algumas lesões. Estromas negros formam-se no córtex da acícula, nas pintas e faixas e emergem por rachaduras da epiderme produzidas pela erupção dos estromas. Sob tempo úmido, os estromas exsudam numerosos conídios em cirros de coloração branca a cinza-esverdeado, em forma de cunha. Espermácios também podem ser exsudados minúsculas gotas esverdeadas, a partir dos espermogônios. A porção final das acículas, com lesões em forma de faixa, seca rapidamente sendo colonizada por outros fungos, enquanto que a parte próxima à base da acícula morre mais lentamente.

Os surtos da doença ocorrem depois de período de chuvas contínuas ou quando acontece um excesso de umidade derivado de irrigação intensa em viveiros. Os acérvulos desenvolvem-se e ficam maturos no fim de agosto e os conídios são liberados em setembro. Os corpos de frutificação passam o inverno nas acículas mortas e o ciclo da doença se renova no verão seguinte com a liberação dos conídios ou ascosporos, sob umidade e temperaturas altas.

IMPORTÂNCIA ECONÔMICA: a doença causa severa queda de acículas em pinheiros chegando a provocar a morte de plantas jovens, em regiões tropicais e subtropicais. Em árvores adultas, produz diminuição do crescimento. Os danos severos manifestam-se na morte de mudas e consequente queda na produção. Os danos principais são verificados em $P$. palustris em estágio de dormência (grass-stage), na fase de muda ou em plantios jovens. Em plantios, perda significativa de crescimento começa a ser observada, quando cerca de $1 / 3$ da copa está afetada. Inicialmente, o crescimento em diâmetro é reduzido e depois em altura, com o aumento da intensidade da queima e queda das acículas. A combinação de doença e competição com plantas daninhas afeta o crescimento da árvore tornando-a 
debilitada e causando a sua morte. A maioria das espécies desenvolve resistência, com o decorrer do tempo, mas árvores de $P$. taeda podem permanecer suscetíveis por muitos anos. A incidência severa da doença concorre para o aumento dos custos de produção, com repercussão direta na expansão da atividade florestal e nos programas de fomento.

O patógeno está registrado no Canadá, EUA, México, Belize, Nicarágua, Costa Rica, Guatemala, Honduras, Colômbia, China, Grécia, ExIugoslávia.

POTENCIAL DE INTRODUCCÃO E CONTROLE: o patógeno pode ingressar no Brasil, em sementes contaminadas com restos de acículas e em mudas doentes, provenientes de países em que $M$. dearnessii foi detectada. As condições de transporte destes materiais não afetam a viabilidade do fungo e as inspeções visuais não permitem a sua detecção.

Os fatores críticos para o estabelecimento e dispersão são a precipitação e a temperatura. Os esporos são liberados em épocas de chuvas com temperaturas médias e altas, nunca sob baixas temperaturas, próximas a 2 ${ }^{\circ} \mathrm{C}$. Nos EUA, o período de infecção concentra-se desde o fim de junho até o início de julho. Para a germinação dos esporos é necessária a presença de umidade sobre as acículas. O período de incubação é variável dependendo da idade e do hospedeiro, de um a dois meses em acículas jovens e de quatro a sete meses em acículas adultas. A forma de disseminação natural é através do transporte de ascosporos pelo vento e pelo salpique dos conídios causado pelas gotas de chuva.

\section{Mycosphaerella gibsonii H. Evans}

SINONIMIA: Cercoseptoria pini-densiflorae (Hori \& Nambu) Deighton (fase assexual)

HOSPEDEIROS: as espécies altamente suscetíveis com apreciável mortalidade são P. attenuata, $P$. caribaea, $P$. kesiya, $P$. muricata, $P$. oocarpa, $P$. pseudostrobus, $P$. radiata e $P$. roxburghii. As espécies suscetíveis mas com pouca mortalidade são $P$. canariensis, $P$. massoniana e $P$. merkusii. As espécies pouco suscetíveis são $P$. elliottii, $P$. greggii, $P$. maximinoi, $P$. palustris, $P$. patula, $P$. strobus, $P$. taeda, $P$. tecunumanii e $P$. wallichiana. são citados $P$. densiflora, $P$. echinata, $P$. pinaster, $P$. tenuifolia, $P$. thumbergii, Consideram-se resistentes $P$. clausa.

SINTOMATOLOGIA: os sintomas da doença aparecem em viveiros, primeiramente, na forma de lesões verde-pálidas sobre acículas, as quais rapidamente tornam-se amarelas, depois marrons e finalmente marromacinzentada. Eventualmente, toda a acícula pode morrer tornar-se cinza, formando linhas constituídas de pequenas fuligens, indicando a presença de conidióforos e conídios. A disseminação da doença acontece através de conídios levados pelo ar, os quais são produzidos em grande número sobre a copa doente ou morta. As acículas mais inferiores são primeiramente atacadas. A doença, então, dissemina-se lentamente para cima. Em mudas severamente 
atacadas, somente o broto terminal permanece verde, enquanto todas as acículas na haste são mortas pelo patógeno. Mudas infectadas podem morrer em decorrência da doença.

Ainda que na maioria das espécies de Pinus o dano seja limitado ao $1^{\circ}$ e $2^{\circ}$ ano de idade, as espécies $P$. radiata, $P$. pinaster, e $P$. halepensis, sofrem igualmente ataques em plantios jovens. A sintomatologia da planta doente pode ser confundida com o ataque de $M$. pini, mas a diferenciação é dada pela análise dos conídios.

IMPORTÂNCIA ECONÔMICA: a doença causa leve a severa queima de acículas, com queda prematura das mesmas, da parte inferior da copa de mudas com mais de dois meses de idade, em muitos países tropicais e subtropicais. Esta causa o lento crescimento das mudas e, em alguns caos, a mortalidade em até $85 \%$. As espécies resistentes podem ter uma pequena proporção da copa afetada, mas sofrem pouca redução no crescimento e não ocorre mortalidade.

A severidade da doença está relacionada com a resistência das espécies e com as condições ambientais que afetam hospedeiro e patógeno. Espécies resistentes podem ser significativamente afetadas em condições altamente favoráveis ao fungo ou totalmente desfavoráveis ao hospedeiro. Várias espécies desenvolvem resistência no segundo ou terceiro ano de idade, entretanto, árvores severamente infectadas podem permanecer dominadas e queimadas por muitos anos. Tais árvores normalmente morrem pela competição com as árvores dominantes e plantas daninhas. Em algumas situações, em indivíduos altamente suscetíveis como $P$. radiata e $P$. canariensis, a infecção pode ocorrer em árvores mais velhas.

O patógeno está relatado na África, Malawi, Rodésia, Tanzânia, Zâmbia. Na América Central foi encontrado na Nicarágua. Na Ásia, os registros foram feitos em Hong Kong, Índia, Japão, Coréia, Malásia, Filipinas, Taiwan, Vietnam do Norte, Sri Lanka.

POTENCIAL DE INTRODUCCÃO E CONTROLE: o fungo pode ingressar por meio de sementes de Pinus com restos de acículas doentes ou mudas infectadas. As condições de transporte, aparentemente não afetam a viabilidade do fungo. No Japão e Taiwan, a doença é o maior obstáculo para a produção de muda, com mortalidade entre 50 e $80 \%$, em $P$. densiflora e $P$. thumbergii. Na Tanzânia, severas desfolhas e morte de plantas jovens foram observadas em $P$. radiata. A forma natural de dispersão é através dos conídios levados pelo vento e o movimento de material infectado, seja por mudas ou semente contaminada com restos de acículas doentes.

O controle pode ser obtido pela aplicação de pulverizações com fungicidas à base de cobre, em intervalos quinzenais, durante os meses mais úmidos. 


\section{Xanthomonas populi (Ridé) Ridé \& Ridé \\ SINONIMIA: Aplanobacter populi Ridé}

HOSPEDEIROS: variedades cultivadas e híbridos de Populus spp. Diferenças consideráveis na suscetibilidade são verificadas entre espécies, cultivares e clones. As espécies mais suscetíveis são $P$. balsamifera, $P$. tacamahaca, $P$. trichocarpa, $P$. deltoides e $P$. euramericana. $P$. nigra é altamente resistente. Os clones suscetíveis e resistentes estão distribuídos entre os álamos da secção Tacamahaca. Os membros do grupo Regenerata tendem a ser suscetíveis.

SINTOMATOLOGIA: na primavera, muitas gemas falham e não se abrem no ramos jovens e são observados os sintomas na base das gemas, na forma de áreas ligeiramente inchadas com rachaduras superficiais que podem exsudar um muco denso e cinza. Nesses pontos, grandes cancros podem se desenvolver por várias estações, inclusive com invasão de outros microrganismos e causar a morte rápida da parte distal do ramo. A infecção do tronco ou dos ramos conduz ao desenvolvimento de uma sucessão de cicatrizes inchadas, mais ou menos trincadas, por onde também pode fluir um denso exsudato cinza, na primavera. $\mathrm{Na}$ ausência deste exsudato, a bactéria pode localizar-se através da região necrótica, a qual revela tecidos internos translúcidos, vitrificados e pegajosos. Os clones altamente suscetíveis são freqüentemente anelados antes do final do segundo verão seguinte à infecção, ou podem desenvolver cancros altamente erumpentes. Nos clones menos suscetíveis, encontram-se pequenas lesões ou somente um calo cicatricial áspero sobre a ferida. Em clones altamente resistentes, não se formam cancros e as feridas são cicatrizadas.

IMPORTÂNCIA ECONÔMICA: a doença se estende pela Irlanda, Polônia e o Reino Unido, estando localmente estabelecida na Alemanha, Austria, Bélgica, ex-Checoslovaquia, França, Hungria, Holanda, Romênia, exUnião Soviética e Ioguslávia. O cancro bacteriano é uma séria enfermidade, podendo chegar a anelar o tronco e causar declínio e seca de ponteiro das árvores. Indivíduos infectados sofrem uma diminuição do crescimento, com deterioração da qualidade da madeira, como resultado da infecção.

POTENCIAL DE INTRODUÇÃO E CONTROLE: estacas infectadas e madeira com cancros são formas de introdução em locais isentos da doença. Esta pode ser disseminada pelo inseto vetor. O controle pode ser efetuado pela eliminação das árvores infectadas e pela cirurgia de tronco. Sem dúvida, o cultivo de clones resistentes é a medida mais adequada. A detecção da bactéria é muito difícil. Todavia, se um cancro ou um exsudato está presente, exames ao microscópio podem revelar a presença da bactéria. A madeira de países onde existe a bactéria deve ser inspecionada para a presença de cancros ou exsudatos, bem como o material propagativo originário destas regiões. 
As principais vias de introdução destes patógenos quarentenários, para o Brasil, são na forma de material para propagação vegetativa, como sementes ou árvores de Natal de coníferas contaminadas ou estacas de salicáceas. Para a importação destes materiais de países, onde estes patógenos estão presentes, existe uma regulamentação que prevê uma série de requisitos fitossanitários, a fim de mitigar e prevenir os riscos de introdução dos mesmos. Estes requisitos, vão desde a exigência da produção de materiais de propagação de áreas livres, ou sob supervisão oficial até a inspeção de ingresso e quarentena interna pósingresso.

O trabalho de identificação do estatus quarentenário de diferentes pragas exóticas é dinâmico, visando proteger o patrimônio florestal do país. Além disso, deve-se manter um serviço efetivo de vigilância e de prospecção, a fim de se fazer detecção precoce destas pragas para que se tomem medidas de erradicação e/ou controle.

\section{BIBLIOGRAFIA CITADA}

ALMEIDA, M.P. de; RODRIGUES, J.M.; GALANTE, M. O nemátodo da madeira do pinheiro - uma nova doença na floresta portuguesa. Revista Florestal, Lisboa, v.12, n.1/2, p.4-9, 1999.

GIBSON, I.A.S. Diseases of forest trees widely planted as exotics in the tropics and southern hemisphere. Part II, the genus Pinus. Kew, 1978, 135p.

HIRATSUKA, Y. Forest tree disease of the prairie provinces. Information Report Nor-X-286, Edmonton. 142p. 1987.

OEPP/EPPO. Cronartium spp. (non-european). Data sheets on quarantine organisms. Paris, European and Mediterranean Plant Protection Organization. 9p. 1977.

MAMIYA, Y. Pathology of the pine wilt disease caused by the pinewood nematode, Bursaphelenchus xylophilus. Annual Review of Phytopathology, Palo alto, v.21, p.201.220, 1983.

SINGH, S. Cercospora needle blight: a potential threat to indigenous pines in India. Indian Forester, v.108, n.4, p.314-318, 1982.

SMITH, I.M.; DUNEZ, J.; LELLIOTT, R.A.; PHILIPS, D.H.; ARCHER, S.A. Manual de enfermedades de las plantas. Madrid: Ediciones MundiPrensa, 1992. 671p.

WINGFIELD, M.J.; BLANCHETTE, R.A.; NICHOLLS, T.H. Is the pine wood nematode an important pathogen in the United States? Journal of Forestry, Bethesda, v.82, n.4, p.232-235, 1984. 